\title{
BIOLOGICAL BEHAVIOR OF BREAST CARCINOMA IN SITU FROM JANUARY 2006 TO DECEMBER 2012
}

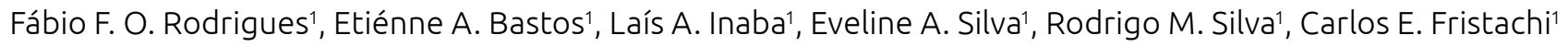

${ }^{1}$ Instituto do Câncer Doutor Arnaldo Vieira de Carvalho - São Paulo (SP), Brazil.

Objectives: Evaluate the incidence of breast carcinoma in situ on patients attended at the Dr Arnaldo Vieira de Carvalho Cancer Institute from 2006 to 2012. Methods: A longitudinal study was performed, descriptive type, retrospective, of patients with breast carcinoma in situ attended at ICAVC in Sao Paulo; data were analyzed on the data base of Microsoft Exce $^{\circledR}$. Results: Were evaluated 267 patients attended at the mastology outpatient clinic, of wich 19 (7.1\%) presented a diagnosis of breast carcinoma in situ by the core needle biopsy, being $13(5 \%)$ histologically confirmed at the biopsy of the surgical part, of these 5\% presented lobular breast carcinoma in situ (CLIS), two (10\%) of the patients with carcinoma in situ presented recurrence, both with invasive component tumor, with hormone receptor positive status and HER-2 positive with high rates of KI67, one patient underwent mastectomy and adjuvant chemotherapy and the other one underwent chemotherapy only, since the first surgical approach was mastectomy; none of these patients presented distant-metastasis until now. Conclusion: With our study, it was observed that the incidence of breast carcinoma in situ at ICAVC was of $7.1 \%$, being compatible with the prevalent incidence of current literature; in addition, it is understood that the presence of breast carcinoma in situ is a marker of risk for invasive carcinoma in relapse. 